\title{
Dikkat Eksikliği Hiperaktivite Bozukluğu Olan Ergenlerde Bilinçli Farkındalık
}

\author{
Nihal YURTERİ 1
}

\section{Öz}

Amaç: Bu çalışmanın amacı tedavi almamış Dikkat Eksikliği Hiperaktivite Bozukluğu (DEHB) tanılı ergenlerde bilinçli farkındalıkla ilişkili faktörlerin incelenmesidir.

Gereç ve Yöntemler: 13-18 yaş arasındaki, DEHB tanısı alan ve tedavi almamış olan 30 ergen ve yaş- cinsiyet açısından eşleştirilmiş sağlıklı 30 ergen çalışmaya alınmıştır. Klinik muayene ve "Okul Çağı Çocukları için Duygulanım Bozuklukları ve Şizofreni Görüşme Çizelgesi-Şimdi ve Yaşam Boyu Versiyonu (ÇDGŞG-ŞY)” tanı görüşmesi ile tanılar ve komorbiditeler belirlenmiş ve dışlama kriteri olan olgular çalışmanın dışında tutulmuştur. DEHB belirtilerini değerlendirmek için "Conners DEHB Anababa Dereceleme Ölçeği Kısa Form-CADÖ", anksiyete belirtilerini değerlendirmek için "Spielberger Durumluk-Sürekli Kaygı Ölçeği- SDKÖ", depresif belirtileri değerlendirmek için "Çocuklar için Depresyon Ölçeği-ÇDÖ" ve bilinçli farkındalık düzeyini değerlendirmek için "Bilinçli Farkındalık Ölçeği- BİFÖ” kullanılmıştır. İstatistiksel değerlendirmede; normal dağılıma uygunluk koşullarına göre "bağımsız örneklemler t testi" ve "Mann-Whitney U testi", korelasyon analizlerinde "Spearman korelasyon analizi" kullanılmıştır.

Bulgular: DEHB grubunda kontrol grubuna göre, CADÖ, SDKÖ ve ÇDÖ ölçek skorları istatistiksel anlamlı olarak yüksek ( $<<0,001)$, BİFÖ toplam skorları ise istatistiksel olarak anlamlı düşük bulunmuştur $(\mathrm{p}<0,001)$. Ayrıca, DEHB grubunda, BİFÖ toplam skorları ile CADÖ, SDKÖ ve ÇDÖ ölçek skorları arasında istatistiksel olarak anlamlı, negatif ve orta etki büyüklüğ̈̈nde korelasyonlar saptanmıştır.

Sonuç: Çalışmamızda, DEHB tanılı ergenlerde sağlıklı ergenlere göre bilinçli farkındalık düzeylerinin düşük olduğu ve DEHB grubunda DEHB, anksiyete ve depresyon belirtilerinin bilinçli farkındalık düzeyleri ile negatif ilişki gösterdiği bulunmuştur. Bu sonuç; bilinçli farkındalık temelli yaklaşımların etkisinin, ergenlerde DEHB belirtileri ve sıklıkla eşlik eden anksiyete, depresyon belirtileri açısından daha ileri çalışmalar ile araştırılmaya değer olduğunu düşündürmektedir. Anahtar Kelimeler: Dikkat eksikliği hiperaktivite bozukluğu; bilinçli farkındalık; ergenler.

\section{Mindfulness in Adolescents with Attention Deficit Hyperactivity Disorder}

\begin{abstract}
Aim: The aim of this study is to examine the factors associated with mindfulness in treatment-naive adolescents diagnosed with Attention Deficit Hyperactivity Disorder (ADHD).

Material and Methods: Thirty treatment-naive adolescents with ADHD aged between 13-18 and age-gender matched 30 healthy adolescents were included in the study. Diagnoses and comorbidities were determined through clinical examination based on DSM 5 and the Interview Schedule for "Affective Disorders and Schizophrenia for School-Age Children- Present and Lifetime Version (Kiddie-SADS-PL)", and cases with exclusion criteria were excluded from the study. "Conners ADHD Parent Rating Scale-revised short form- CPRS-RS" was used to evaluate ADHD symptoms, "Spielberger State-Trait Anxiety Scale- STAI" to evaluate anxiety symptoms, "Child Depression Inventory- CDI" to evaluate depressive symptoms and "Mindful Attention Awareness Scale- MAAS" to evaluate mindfulness. In statistical evaluation, "independent samples $t$ test" and "Mann- Whitney U" test were used according to conformity to normal distribution. "Spearman correlation analysis" was used for correlation analysis.
\end{abstract}

Results: CPRS, STAI and CDI scale scores were found to be statistically significantly higher (p<0.001) and MAAS 
total scores were found to be statistically significantly lower $(\mathrm{p}<0.001)$ in ADHD group compared to control group. In addition, it was determined that MAAS total scores showed statistically significant, negative and moderate effect size correlations with the scores of CPRS, STAI and CDI scales in ADHD group.

Conclusion: Mindfulness levels were found to be lower in ADHD group compared to control group. Additionally, ADHD, anxiety and depression symptoms showed negative correlations with mindfulness levels in adolescents with ADHD. This result suggests that the effects of mindfulness-based approaches are worth investigating with further studies in terms of ADHD symptoms and frequently comorbid anxiety and depression symptoms in adolescents.

Keywords: Attention deficit hyperactivity disorder; mindfulness; adolescents.

\section{GíRIŞ}

Dikkat Eksikliği Hiperaktivite Bozukluğu (DEHB), işlevselliği bozan dikkatsizlik, hiperaktivite ve dürtüsellik semptomları ile karakterize, sık görülen nörogelişimsel bir bozukluktur (1). Dünya genelinde çocuk-ergenlerde yaygınlığının yaklaşık \%2,6-4,5 olduğu bildirilmektedir (2). DEHB, genetik ve çevresel faktörleri birbirine bağlayan çok yönlü ve çok boyutlu etiyolojiye sahiptir (3). DEHB, sıklıkla anksiyete, depresyon, karşıt olma karşıt gelme bozukluğu, davranım bozukluğu gibi çeşitli psikiyatrik bozukluklarla birlikte görülür $(4,5)$. Bu komorbiditelerin yanı sıra; DEHB olan çocuklar, yetişkinlik döneminde de bozukluğun önemli semptomlarını göstermeye devam ederler ve düşük eğitim-istihdam, madde kullanımı, çeşitli psikiyatrik bozukluklar gibi uzun vadeli olumsuz sonuçlar açısından daha büyük risk altındadırlar (6). DEHB' nin ciddi psikiyatrik, akademik, sosyal, ekonomik ve kaza sonucu yaralanmaya bağlı etkileri ve ayrıca DEHB'de birinci sıra tedaviler olan psikofarmakolojik tedavilerde ortaya çıkabilecek kompliyans sorunları, yan etkiler ya da etkinlik yetersizliği durumları göz önüne alındığında; farmakolojik olmayan ancak nöronal mekanizmalara etkili (nöropsikoterapötik) ek tedaviler geliştirmeye yönelik ihtiyaç üzerinde durulmaktadır $(7,8)$. Bu bağlamda, nöropsikoterapötik bir yaklaşım olarak bilinçli farkındalık temelli terapinin, DEHB tedavisinde umut vadeden bir yöntem olduğu öne sürülmüştür (8).

Bilinçli farkındalık, "bireyin yargılamadan dikkatini ana odaklaması ve anda yaşadığı deneyimleri kabullenmesi” şeklinde tanımlanmaktadır (9). Bilinçli olarak farkında olmak demek; dikkatin geçmiş ve gelecekle meşgul olmaması, şu anda olanı yargılamamak veya inkar etmemek, tümüyle şimdiki anda olmak demektir $(9,10)$. Literatürde bilinçli farkındalıkla ilgili; andaki zihinsel durumları tanımak için deneyim üzerinde dikkati sürdürme anlamına gelen 'dikkat regülasyonu' ve deneyime yönelik merak, kabullenme ve açıklık ile karakterize 'anlık deneyimi yönlendirme' şeklinde iki bileşenden bahsedilmektedir (11). Bilinçli farkındalık egzersizlerinin, DEHB tanısını da içeren dışa yönelim bozukluklarının (12) ve anksiyete, depresyon gibi içe yönelim bozukluklarının (13) terapisinde etkili olduğu bildirilmiştir. Bilinçli farkındalık, ayrıca erişkin psikiyatrisinde DEHB olgularında modifiye diyalektik davranışçı terapi yönteminin bir bileşeni olarak kullanılmakta olup, bu çalışmalarda DEHB belirtilerinde iyileşmeler bildirilmiştir $(14,15)$.

Literatürde bilinçli farkındalık temelli terapi müdahalelerinin DEHB tanılı erişkin ve ergenlerde etkileri ile ilgili çeşitli çalışmalar bulunmasına karşın, ilaç tedavisi ya da herhangi bir tedavi almamış olan DEHB tanılı ergenlerde, bilinçli farkındalık ile anksiyete, depresyon belirtileri gibi faktörlerin ilişkisinin incelendiği çalışmaya rastlamadık. Dolayısıyla, bu çalışmanın amacı tedavi almamış DEHB tanılı ergenlerde bilinçli farkındalıkla ilişkili faktörlerin incelenmesidir.

\section{GEREÇ VE YÖNTEMLER}

Örneklem büyüklüğünü belirlemek için literatürdeki benzer bir çalışma baz alınarak olgu grubunda BİFÖ toplam ortalama değerin $52,29 \pm 13,25$ kontrol grubunda ise $68,84 \pm 11,94$ olduğu varsayıldı (16). Buna göre $\% 95$ güven düzeyi ve \%80 güç ile en az örneklem genişliği 22 olarak hesaplandı. Örneklem seçiminde basit rastgele örnekleme yöntemi kullanıldı. Düzce Üniversitesi Çocuk Psikiyatri polikliniğine başvuran 13-18 yaş arasındaki, DEHB tanısı alan tedavi almamış 30 ergen olgu grubu olarak ve çocuk psikiyatri polikliniğine danışma amaçlı başvurup herhangi bir psikopatoloji saptanmayan yaş ve cinsiyet açısından eşleştirilmiş 30 ergen ise kontrol grubu olarak çalışmaya alındı. Çalışmaya dahil edilen ergenlerden sosyodemografik veri formu açıklanarak doldurulması istendi. Klinik muayene, Ruhsal Bozuklukların Tanısal ve Sayımsal El Kitabı- Beşinci Baskı (DSM-5) ve Okul Çağı Çocukları için Duygulanım Bozuklukları ve Şizofreni Görüşme Çizelgesi- Şimdi ve Yaşam Boyu Versiyonu (ÇDGŞG-ŞY) (Kiddie-SADSPL) tanı görüşmesi ile tanılar ve komorbiditeler belirlendi ve dışlama kriteri olan olgular çalışmanın dışında tutuldu. Olgu grubunda kronik fiziksel hastalığı olanlar, bipolar bozukluk, psikotik bozukluk, otizm spektrum bozukluğu, mental retardasyon, madde bağımlılığı komorbiditesi olanlar, kontrol grubunda ise psikiyatrik hastalık, kronik fiziksel/nörolojik hastalık olanlar çalışma dişında tutuldu.

\section{Gereçler}

Okul Çağı Çocukları için Duygulanım Bozuklukları ve Şizofreni Görüşme Çizelgesi- Şimdi ve Yaşam Boyu Versiyonu (ÇDGŞG-ŞY): Klinisyen tarafından çocuk ve ebeveyni ile yapılan, yarı yapılandırılmış psikiyatrik hastalık tarama görüşmesidir (17). Türkçe geçerlik güvenilirlik çalışması yapılmıştır (18). Ayrıca, DSM 5'e göre revize formu da mevcuttur (19). $\mathrm{Bu}$ formun da Türkçe uyarlaması yapılmıştır (20).

Conners DEHB Anababa Dereceleme Ölçeği-yenilenmiş kısa form (CADÖ-KF): Conners ve arkadaşları tarafindan, ebeveynlerce gözlemlenen dikkat eksikliği, hiperaktivite, karşı çıkma karşı gelme belirtilerini ve şiddetini değerlendirmek üzere geliştirilmiş bir ölçektir (21). Geçerlik güvenilirlik çalışması yapılmıştır (22).

Spielberger durumluk-sürekli kaygl ölçeği (SDKÖ): Spielberger tarafindan kaygı seviyelerini ölçmek amacıyla geliştirilmiştir (23). Ergenlerde de geçerlik güvenilirlik çalışması yapılmıştır (24). İlk 20 soru durumluk kaygı düzeyini belirler, ikinci 20 soru sürekli kayg1 düzeyini belirler. Ölçek maddeleri 1-4 puan arasında puanlanır. Ergenlerde Türkçe geçerlik güvenilirlik çalışması yapılmıştır (25). 
Çocuklar için Depresyon Ölçeği (ÇDÖ): Kovacs tarafından 6-17 yaş arası çocuk ve ergenlerde depresyon belirtilerini derecelendirmek için geliştirilmiş olan ölçek, 27 sorudan oluşan, üçlü likert tipi bir ölçektir $(26,27)$. Türkçe geçerlik ve güvenilirlik çalışması yapılmıştır (28). Bilinçli Farkındalık Ölçeği (BİFÖ): Bilinçli Farkındalık düzeylerini ölçmek için 15 maddeden oluşan Brown ve Ryan tarafından geliştirilen BİFÖ kullanılmıştır (29). BİFÖ, 1'den değişen Likert tipi bir ölçek kullanır (neredeyse her zaman) 6'ya (neredeyse hiçbir zaman) kadar olası bir puan aralığı ile sonuçlanır. BİFÖ'nün Türkçe geçerlik ve güvenirliği Özyesil ve ark. tarafından yapılmıştır (30). Ergenlerde Türkçe geçerlik güvenirlik çalışması ise Yavuz ve ark. tarafından yapılmıştır (31).

Tablo 1. DEHB ve kontrol grubunda klinik parametreler

\begin{tabular}{|l|c|c|c|c|}
\hline Ortanca (KAA) & $\begin{array}{c}\text { DEHB } \\
(\mathbf{n}=\mathbf{3 0})\end{array}$ & $\begin{array}{c}\text { Kontrol } \\
(\mathbf{n}=\mathbf{3 0})\end{array}$ & $\mathbf{Z} / \mathbf{t}$ & $\mathbf{p}$ \\
\hline $\begin{array}{l}\text { CADÖ-KF } \\
\text { dikkat eksikliği }\end{array}$ & $\begin{array}{c}12,50 \\
(5)\end{array}$ & $0,50(3)$ & $-6,715$ & $<0,001$ \\
\hline $\begin{array}{l}\text { CADÖ-KF } \\
\text { hiperaktivite }\end{array}$ & $\begin{array}{c}11 \\
(3,25)\end{array}$ & $1,00(2)$ & $-6,705$ & $<0,001$ \\
\hline $\begin{array}{l}\text { CADÖ-KF } \\
\text { karşı1 olma } \\
\text { karşıl gelme }\end{array}$ & $\begin{array}{c}9 \\
(5,25)\end{array}$ & $2,00(4)$ & $-5,759$ & $<0,001$ \\
\hline $\begin{array}{l}\text { SDKÖ } \\
\text { Durumluk }\end{array}$ & $\begin{array}{c}36,50 \\
(14,75)\end{array}$ & $\begin{array}{c}29 \\
(10,25)\end{array}$ & $-3,584$ & $<0,001$ \\
\hline SDKÖ Sürekli & $\begin{array}{c}39,50 \\
(13,75)\end{array}$ & $34(11)$ & $-3,589$ & $<0,001$ \\
\hline $\begin{array}{l}\text { ÇDÖ } \\
\text { (ortalama } \pm \text { SD) }\end{array}$ & $\begin{array}{c}13,17 \pm \\
4,63\end{array}$ & $\begin{array}{c}6,90 \pm \\
3,57\end{array}$ & $5,872 *$ & $<0,001 *$ \\
\hline BİFÖ & $\begin{array}{c}49,50 \\
(11,25)\end{array}$ & $\begin{array}{c}58 \\
(13,75)\end{array}$ & $-3,522$ & $<0,001$ \\
\hline
\end{tabular}

Mann-Whitney U testi, *t testi, DEHB: Dikkat Eksikliği Hiperaktivite Bozukluğu, BİFÖ: Bilinçli Farkındalık Ölçeği, CADÖ-KF: Conners Anababa Dereceleme Ölçeği- kısa form, SDKÖ: Spielberg, SürekliDurumluk Kaygı Ölçeği, ÇDÖ: Çocuklar için Depresyon Ölçeği, KAA: Kartiller arası aralık, SD:Standart sapma

\section{Çalışmanın Etik Yönü}

Etik kurul izni (Karar No:2019/15) Düzce Üniversitesi Girişimsel Olmayan Çalışmalar Etik Kurulu'ndan alınarak çalışmaya başlandı. Çalışmaya dahil edilen tüm olguların sözel olarak bilgilendirilmiş onamları ve ebeveynlerinden de çalışmanın amacı anlatıldıktan sonra bilgilendirilmiş onamları alındı. Çalışma, araştırma ve yayın etiği kurallarına uyularak gerçekleştirildi.

\section{İstatistiksel Analiz}

İstatistiksel inceleme için SPSS 21 (SPSS Inc, Chicago, IL, USA) programı kullanıldı. Kategorik değişkenler için ki kare testi kullanıldı. Sürekli değişkenlerin olgu ve kontrol gruplarında normal dağılıp dağılmadığını bulmak için Shapiro Wilk testi kullanıldı. Normal dağılıma uyan verilerde bağımsız örneklemler t test, uymuyorsa MannWhitney U test kullanıldı. Olgu-kontrol gruplarında DEHB bulgu şiddeti, anksiyete ve depresyon belirti şiddeti ile bilinçli farkındalık ölçeği arasındaki ilişkiler için Spearman korelasyon analizleri yapıldı. Analizlerde p değeri 0,05 olarak alındı tüm ve analizler çift yönlü olarak gerçekleştirildi. Çalışmanın güç analizinde; alfa 0,05 (çift yönlü) alındığında, 60 kişilik örneklem büyüklüğümüzde BİFÖ ölçek sonuçlarımıza göre $\% 95$ güç elde edildi.

\section{BULGULAR}

Olgu ve kontrol grupları yaş ve cinsiyet açısından bire bir eşleştirilmiş olup, yıl olarak yaş ortalamaları 14,10 \pm 1,16 y1l ve cinsiyet (her iki grupta 20 erkek ve $10 \mathrm{k1z}$ ) açısından gruplar arasında fark yoktu ( $\mathrm{p}=0,999)$. Sosyoekonomik açıdan; ailenin geliri, anne ve baba eğitim düzeyleri açısından da olgu ve kontrol grupları arasında farklılık saptanmadı $(\mathrm{p}=0,418 ; 0,559 ; 0,458$ sirasiyla).

DEHB grubunda sağlıklı kontrol grubuna göre; CADÖ dikkat eksikliği, CADÖ hiperaktivite, SDKÖ anksiyete ve ÇDÖ ölçek skorları istatistiksel anlamlı olarak yüksek saptand $1(p<0,001$ Tablo 1). BİÖ toplam skorları ise DEHB grubunda kontrol grubuna göre istatistiksel anlamlı olarak düşük bulundu ( $\mathrm{p}<0,001$ Tablo 1$)$.

DEHB grubunda; Spearman korelasyon analizi değerlendirilen BİFÖ toplam skorları ile CADÖ dikkat eksikliği, CADÖ hiperaktivite, SDKÖ anksiyete ve ÇDÖ ölçek skorları arasındaki ilişkiler Tablo 2'de gösterilmiştir. Buna göre, BİFÖ toplam skorlarının; CADÖ, SDKÖ anksiyete ve ÇDÖ ölçek skorları ile anlamlı, negatif ve orta etki büyüklüğünde korelasyonlar gösterdiği saptandi.

\section{TARTIŞMA VE SONUÇ}

Bu çalışmada DEHB tanılı ergenlerde bilinçli farkındalık ile ilişkili faktörleri, özellikle bilinçli farkındalık ile dikkat eksikliği hiperaktivite bozukluğu, depresyon ve anksiyete belirtilerinin ilişkisini incelemeyi amaçladık.

Çalışmamızın sonucunda DEHB grubunda sağlıklı kontrol grubuna göre; DEHB belirtileri ve anksiyete, depresyon belirti puanları anlamlı olarak yüksek saptanmıştır. Ayrıca, DEHB grubu ergenlerde, DEHB belirtileri ve anksiyete, depresyon belirti puanları ile bilinçli farkındalık düzeyleri arasında anlamlı negatif korelasyonlar saptanmıştır. Literatürde, çalışmamızın sonuçlarını destekler şekilde; depresyon, anksiyete ve somatizasyon belirtileri ile erişkin psikiyatriye başvuran erişkin olgular ve sağlıklı kontrol grubu ile yapılan bir çalışmada; olgu grubunda kontrol grubuna göre DEHB, anksiyete, depresyon belirtileri anlamlı yüksek ve bilinçli farkındalık düzeylerinin anlamlı düşük olduğu saptanmış ve olgu grubunda hem DEHB, hem de anksiyete, depresyon belirtileri ile bilinçli farkındalık düzeyleri arasında anlamlı negatif korelasyonlar olduğu bildirilmiştir. Aynı çalışmada ayrıca; DEHB ve depresyon belirtilerinin bilinçli farkındalık düzeylerini yordadığı bulunmuştur (16).

Yine çalışmamızın sonuçlarını destekler şekilde; çoğunluğu psikostimulan tedavi almakta olan DEHB olan erişkin ve ergenler ile yapılan bir çalışmada; 8 haftalık bilinçli farkındalık egzersizi ile hem erişkin hem de ergenlerde DEHB belirtilerinde ve erişkin grubunda anksiyete ve depresyon belirtilerinde anlamlı azalma saptanmıştır (32).

Çalışmamızla uyumlu olarak, DEHB tanılı erişkinlerde yapılan randomize kontrollü bir çalışmada; 6 haftalık bilinçli farkındalık temelli bilişsel davranışçı terapi uygulanan olgu grubunda, bekleme listesinden oluşan kontrol grubuna göre bilinçli farkındalık düzeylerinde ve 
Tablo 2. DEHB grubunda bilinçli farkındalık ile DEHB, anksiyete ve depresyon ölçek skorları korelasyonları

\begin{tabular}{|c|c|c|c|c|c|c|c|c|c|c|c|c|}
\hline & \multicolumn{2}{|c|}{$\begin{array}{c}\text { CADÖ } \\
\text { Dikkat eksikliği }\end{array}$} & \multicolumn{2}{|c|}{$\begin{array}{c}\text { CADÖ } \\
\text { Hiperaktivite }\end{array}$} & \multicolumn{2}{|c|}{$\begin{array}{l}\text { CADÖ } \\
\text { KOKGB }\end{array}$} & \multicolumn{2}{|c|}{$\begin{array}{c}\text { SDKÖ } \\
\text { Durumluk Anksiyete }\end{array}$} & \multicolumn{2}{|c|}{$\begin{array}{c}\text { SDKÖ } \\
\text { Sürekli Anksiyete }\end{array}$} & \multicolumn{2}{|c|}{$\begin{array}{c}\text { ÇDÖ } \\
\text { Depresyon }\end{array}$} \\
\hline & $r$ & (n) & & $n$ & $\mathrm{r}$ & $p$ & (2) & n & & & $\mathrm{r}$ & $p$ \\
\hline Bं̈FÖ & $-0,462$ & $0,010^{*}$ & $-0,423$ & $0,020^{*}$ & $-0,063$ & 0,743 & $-0,433$ & $0,017^{*}$ & $-0,472$ & $0,009 *$ & $-0,501$ & $0,005^{*}$ \\
\hline
\end{tabular}

Spearman korelasyon testi, *BİFÖ: Bilinçli Farkındalık Ölçeği, CADÖ-KF: Conners Anababa, Dereceleme Ölçeği- kısa form, SDKÖ: Spielberg

Sürekli-Durumluk Kaygı Ölçeği, ÇDÖ: Çocuklar için Depresyon Ölçeği

nöropsikolojik performansta anlamlı artış ve dikkat eksikliği, hiperaktivite-dürtüsellik, anksiyete ve depresyon puanlarında ise anlamlı azalma bildirilmiştir (33).

Bir metaanaliz çalışmasında çalışmamızın sonuçları ile uyumlu şekilde, bilinçli farkındalık temelli terapilerin DEHB temel semptomları için büyük etki boyutu bildirilmiş ve dikkat eksikliği üzerindeki etkisi hiperaktivite / dürtüsellikten daha büyük saptanmıştır. Yazarlar bu sonucu, bilinçli farkındalık temelli terapilerin DEHB temel semptomlarını önemli ölçüde azaltabileceği şeklinde yorumlamışlardır (34).

Bilinçli farkındalığın, kişi çevreye yoğun bir şekilde dikkat etmediği, odaklanmadığı ve kişisel dürtüleri, irdelenmemiş algılarıyla hareket etmeye başladığ ortadan kaybolmakta olduğu belirtilmiştir (35). Bahsedilen sorunların DEHB temel belirtileriyle örtüştüğü bilindiğinden, çalışmamızda saptanan dikkat eksikliği ve hiperaktivite-dürtüsellik belirtileri ile bilinçli farkındalık düzeylerinin negatif korelasyon göstermesi sonucu literatür ile uyumludur. Ek olarak, yine çalışmamızın sonucunu destekler şekilde, nörogörüntüleme çalışmalarında hem bilinçli farkındalık ve hem de DEHB açısından önemli olan "anterior singulat" ve "dorsolateral prefrontal korteks" gibi ortak beyin bölgeleri gösterilmiştir (36).

Ayrıca çalışmamızdaki sonuçları destekler şekilde; bilinçli farkındalık egzersizlerinin DEHB'de sorunlu olan dikkat düzenlenmesi ve yürütücü işlevler üzerine pozitif etkileri bildirilmektedir (37-39). Bir çalışmada, bilinçli farkındalık egzersizlerinin çocuklarda öğretmen ve ebeveyn bildirimlerinde yürütücü işlevleri geliştirdiği gösterilmiştir (40). Başka bir çalışmada, 20 dakikalık bilinçli farkındalık egzersizi, görsel uzamsal işlemleme, işleyen bellek ve yürütücü işlevler görev performansında anlamlı gelişme ile ilişkili bulunmuştur (41). Sinirbilimde, dinlenme durumunda aktif olan ve görev performansı sırasında pasif olması beklenen, DEHB gibi durumlar nedeniyle disfonksiyonel olduğunda ise "sürekli dikkat", "set değiştirme" (dikkat odağını çeşitli uyaranlar arasında değiştirme), "dürtü kontrolü” ve "çalışma belleği" gibi dikkat süreçlerini içeren yürütücü işlevlerin bozuklukları ile ilişkili olan, "default mode network" terimiyle belirtilen "varsayılan mod ağı" tanımlanmıştır $(8,42)$. Bilişsel farkındalık egzersizlerinin, "varsayılan mod ağı"nın disfonksiyonel işleyişini iyileştirerek DEHB'de zihin gezinmelerini ve dikkat çelinebilirliğini azaltmaya yardımcı olabileceği bildirilmiştir $(8,43)$.

Literatürde bilinçli farkındalığın, yürütücü işlevlerden dikkat sürdürme kapasitesini ve dikkat odağını çeşitli uyaranlar arasında değiştirme kapasitesini arttırarak kişinin dikkatini depresif ya da kaygılı ruminasyonlardan, "şimdi ve bu ana" çekme potansiyelini de arttırdığ 1 ve kişinin duygu düzenleme potansiyelini geliştirdiği vurgulanmıştır (37-39). Benzer şekilde bilinçli farkındalığın, andaki durumlara karşı tepkiselliği azaltan bir beceri olduğu ve gençler için bilişsel farkındalık temelli yaklaşımların, duygu düzenlemeyi geliştirmek adına potansiyel faydaya sahip olduğu bildirilmiştir $(44,45)$. DEHB' deki duygu düzenleme sorunları ile örtüşen beyin bölgelerini ve bilinçli farkındalık ile ilişkili değişimlerini inceleyen nörogörüntüleme çalışmalarında; dorsal ve ventromedial bölgeleri içeren "prefrontal korteks", "hipokampus" ve "amigdala" dahil olmak üzere ilgili alanlar, bilişsel farkındalık egzersizinden sonra duygu düzenlemedeki iyileşme ile ilişkilendirilmiş olup, bu alanlar aynı zamanda DEHB tanısı olan kişilerde duygusal işlevsellik ile de ilgili bulunmuştur $(39,46)$. Bu bilgilerle uyumlu şekilde DEHB'de bilinen duygu düzenleme sorunları ile ilgili olarak çalışmamızda; DEHB tanılı ergen grubunda bilinçli farkındalık düzeyleri ile anksiyete, depresyon gibi duygu düzenleme sorunlarıyla ilişkili belirtiler arasında anlamlı negatif korelasyonlar saptanmıştır. Yine çalışmamızla uyumlu olarak literatürde, anksiyete bozukluğu ve depresyon tanısı olan kişilerde bilinçli farkındalık düzeyinin anlamlı olarak daha düşük olduğu ve bilinçli farkındalık temelli tedavilerle yaşam kalitesinde anlamlı artış bildirilmiştir (47). Ek olarak, bilinçli farkındalık temelli yöntemlerin erişkin depresyonunda olduğu gibi, ergen depresyonunda da etkili olduğu saptanmıştır $(48,49)$.

Sonuç olarak bilinçli farkındalıkla ilgili çalışmalar; bilinçli farkındalık egzersizlerinin DEHB'de en sorunlu alanlar olan dikkat, yürütücü işlevler ve duygu düzenleme üzerine etki göstererek DEHB'de fayda sağlayabileceğini göstermiştir. Bu nedenle bilinç farkındalık egzersizlerinin DEHB'de kullanılmasının kavramsal olarak makul olduğu ve umut vadetmekte olduğu belirtilmiştir (36).

Çalışmamızın kısıtlılıkları olarak; kesitsel tanımlayıcı desende bir çalışma olması, kısıtlı örneklem büyüklüğü sayılabilir, bu nedenlerden dolayı çalışmamızın genellenebilirliği kısıtlıdır. Çalışmamızın güçlü yanları arasında ise; çalışmamızda tanının standardize yapılandırılmış psikiyatrik değerlendirmeler ile belirlenmiş olması, olgu grubunun tedavi almamış homojen bir grup olması ve kontrol grubunun olgu grubu ile yaş ve cinsiyet açısından birebir eşleştirilmiş olması, küçük örneklem büyüklüğüne karşın çalışmanın gücünün yüksek olması belirtilebilir.

Çalışmamızda, DEHB tanılı ergenlerde bilinçli farkındalık düzeylerinin sağlıklı ergenlere göre düşük olduğu ve DEHB, anksiyete ve depresyon belirtileri arttıkça bilinçli farkındalık düzeylerinin düştüğü saptanmıştır. $\mathrm{Bu}$ sonuç, bilinçli farkındalık temelli yaklaşımların, ergenlerde DEHB ve sıklıkla eşlik eden anksiyete, depresyon belirtileri açısından daha ileri 
çalışmalar ile araştırılmaya değer olduğunu düşündürmektedir.

\section{KAYNAKLAR}

1. American Psychiatric Association. Diagnostic and statistical manual of mental disorders (DSM-5). 5th ed. Arlington: American Psychiatric Association; 2013.

2. Polanczyk GV, Salum GA, Sugaya LS, Caye A, Rohde LA. Annual research review: A meta-analysis of the worldwide prevalence of mental disorders in children and adolescents. J Child Psychol Psychiatry. 2015; 56(3): 345-65.

3. Faraone SV, Biederman J, Spencer T, Wilens $\mathrm{T}$, Seidman LJ, Mick E, et al. Attention-deficit/ hyperactivity disorder in adults: An overview. Biol Psychiatry. 2000; 48(1): 9-20.

4. Spencer TJ, Biederman, Mick E. Attentiondeficit/ hyperactivity disorder: Diagnosis, lifespan, comorbidities, and neurobiology. Journal of Pediatric Psychology. 2007; 32(6): 631-42.

5. Reale L, Bartoli B, Cartabia M, Zanetti M, Costantino MA, Canevini MP, et al. Comorbidity prevalence and treatment outcome in children and adolescents with ADHD. European Child \& Adolescent Psychiatry. 2017; 26(12): 1443-57.

6. Nigg JT. Attention-deficit/hyperactivity disorder and adverse health outcomes. Clin Psychol Rev. 2012; 33(2): 215-28.

7. Hinshaw SP, Arnold LE, MTA Cooperative Group. Attention-deficit hyperactivity disorder, multimodal treatment, and longitudinal outcome: Evidence, paradox, and challenge. Wiley Interdiscip Rev Cogn Sci. 2015; 6(1): 39-52.

8. Bachmann K, Lam AP, Philipsen A. Mindfulnessbased cognitive therapy and the adult ADHD brain: A neuropsychotherapeutic perspective. Frontiers in Psychiatry. 2016; 7: 117. doi: 10.3389/fpsyt.2016.00117.

9. Kabat-Zinn J. Mindfulness-based interventions in context: Past, present, and future. Clin Psychol Sci Pract. 2003; 10(2): 144-56.

10. Germer CK, Siegel R, Fulton P. Mindfulness and psychonyanaponika therapy. New York: Guilford Press; 2005.

11. Bishop SR, Lau M, Shapiro S, Carlson L, Anderson ND, Carmody J, et al. Mindfulness: A proposed operational definition. Clinical Psychology: Science and Practice. 2004; 11(3): 230-41.

12. Bögel SM, Hoogstad B, van Dun L, Schutter S, Restifo K. Mindfulness training for adolescents with externalizing disorders and their parents. Behav Cogn Psychother. 2008; 36(2): 193-210.

13. Semple RJ, Reid EFG, Miller L. Treating anxiety with mindfulness: An open trial of mindfulness training for anxious children. J Cogn Psychother. 2005; 19(4): 379-91.

14. Hesslinger B, Tebartz van Elst L, Nyberg E, Dykierek $\mathrm{P}$, Richter H, Berner $\mathrm{M}$, et al. Psychotherapy of attention deficit hyperactivity disorder in adults A pilot study using a structured skills training program. Eur Arch Psychiatry Clin Neurosci. 2002; 252(4): 177-84.
15. Hirvikoski T, Waaler E, Alfredsson J, Pihlgren C, Holmström A, Johnson A, et al. Reduced ADHD symptoms in adults with ADHD after structured skills training group: Results from a randomized controlled trial. Behav Res Ther. 2011; 49(3): 175-85.

16. Yavuz BG, Yavuz M, Onal A. Examining the factors that are correlated with mindfulness with a focus on attention deficit hyperactivity symptoms. Perspect Psychiatr Care. 2018; 54(4): 596-602.

17. Kaufman J, Birmaher B, Brent D, Rao U, Flynn C, Moreci $\mathrm{P}$, et al. Schedule for affective disorders and schizophrenia for school-age children-present and lifetime version (K-SADS-PL): Initial reliability and validity data. J Am Acad Child Adolesc Psychiatry. 1997; 36(7): 980-8.

18. Gökler B, Ünal F, Pehlivantürk B, Çengel-Kültür E, Akdemir D, Taner Y. The reliability and validity of the Turkish version of schedule for affective disorders and schizophrenia-present and lifetime version for school children. Turk J Child Adolesc Ment Health. 2004; 11(3): 109-16.

19. Kaufman J, Birmaher B, Axelson D, Pereplitchikova F, Brent D, Ryan N. Schedule for affective disorders and schizophrenia for school-aged children: present and lifetime version (K-SADS-PL) DSM-5 working draft. New Haven: Yale University Child and Adolescent Research and Education; 2016.

20. Ünal F, Öktem F, Çetin Çuhadaroğlu F, Çengel Kültür SE, Akdemir D, Foto Özdemir D, et al. Reliability and validity of the schedule for affective disorders and schizophrenia for school-age childrenpresent and lifetime version, DSM-5 November 2016Turkish Adaptation (K-SADS-PL-DSM-5-T). Turk Psikiyatri Derg. 2019; 30(1): 42-50.

21. Conners CK, Sitarenios G, Parker JD, Epstein JN. The revised conners' parent rating scale (CPRS-R): factor structure, reliability, and criterion validity. J Abnorm Child Psychol. 1998; 26(4): 257-68.

22. Kaner Ş, Büyüköztürk Ş, İşeri E. Conners parent rating scale-revised short: Turkish standardization study. Arch Neuropsychiatr. 2013; 50(2): 100-9.

23. Spielberger CD, Gorsuch RL, Lushene R, Vagg PR, Jacobs GA. Manual for the state-trait anxiety inventory. Palo Alto: Consulting Psychologists Press; 1983.

24. Carey MP, Faulstich ME, Carey TC. Assessment of anxiety in adolescents: Concurrent and factorial validities of the trait anxiety scale of Spielberger's state-trait anxiety inventory for children. Psychological Reports. 1994; 75(1): 331-8.

25. Öner N, Le Compte A. Süreksiz durumluk/Sürekli kaygı envanteri el kitabı. 2. baskı. İstanbul: Boğaziçi Üniversitesi Yayınevi; 1998.

26. Kovacs M. Rating scales to assess depression in school- aged children. Acta Paedopsychiatrica: International Journal of Child and Adolescent Psychiatry. 1981; 46(5-6): 305-15.

27. Kovacs M. The childrens' depression inventory (CDI). J Psychopharmacol Bull. 1985; 21(4): 995-8.

28. Öy B. Çocuklar için depresyon ölçeği: Geçerlik ve güvenirlik çalışması. Türk Psikiyatri Derg. 1991; 2(2): 132-6. 
29. Brown KW, Ryan RM. The benefits of being present: Mindfulness and its role in psychological well-being. J Pers Soc Psychol. 2003; 84(4): 822-48.

30. Özyeşil Z, Arslan C, Kesici Ş, Deniz ME. Bilinçli farkındalık ölçeğini Türkçeye uyarlama çalışması. Eğitim ve Bilim. 2011; 36(160): 224-35.

31. Yavuz M, Çalkan B, Sönmez E, Tetik G, Kadak MT. Ergen yaş grubunda bilinçli farkındalık ölçeğinin psikometrik özelliklerinin incelenmesi. Turk J Child Adolesc Ment Health. 2019; 26(2): 68-74.

32. Zylowska L, Ackerman DL, Yang MH, Futrell JL, Horton NL, Hale TS, et al. Mindfulness meditation training in adults and adolescents with ADHD: A feasibility study. J Atten Disord. 2008; 11(6): 737-46.

33. Gu Y, Xu G, Zhu Y. A Randomized controlled trial of mindfulness-based cognitive therapy for college students with ADHD. J Atten Disord. 2018; 22(4): 388-99.

34. Xue J, Zhang Y, Huang Y. A meta-analytic investigation of the impact of mindfulness-based interventions on ADHD symptoms. Medicine (Baltimore). 2019; 98(23): e15957.

35. Deci EL, Ryan RM. Self determination theory: When mind mediates behavior. The Journal of Mind and Behavior. 1980;1(1): 33-43.

36. Mitchell JT, McIntyre EM, English JS, Dennis MF, Beckham JC, Kollins SH. A pilot trial of mindfulness meditation training for ADHD in adulthood: Impact on core symptoms, executive functioning, and emotion dysregulation. J Atten Disord. 2017; 21(13): 1105-20.

37. Teasdale JD, Segal Z, Williams JM. How does cognitive therapy prevent depressive relapse and why should attentional control (mindfulness) training help. Behav Res Ther. 1995; 33(1): 25-39.

38. Shapiro SL, Schwartz GE. The role of intention in self-regulate: Toward intentional systemic mindfulness. In: Zeidner M, Pintrich PR, Boekaerts M, editors. Handbook of self regulation. San Diego: Academic Press; 2000. p. 253-73.

39. Hölzel BK, Lazar SW, Gard T, Schuman-Olivier Z, Vago DR, Ott U. How does mindfulness meditation work? proposing mechanisms of action from a conceptual and neural perspective. Perspectives on Psychological Science. 2011; 6(6): 537-59.

40. Flook L, Smalley SL, Kitil MJ, Galla BM, KaiserGreenland S, Locke J, et al. Effects of Mindful awareness practices on executive functions in elementary school children. Journal of Applied School Psychology. 2010; 26(1): 70-95.

41. Zeidan F, Johnson SK, Diamond BJ, David Z, Goolkasian P. Mindfulness meditation improves cognition: Evidence of brief mental training. Consciousness and Cognition. 2010; 19(2): 597-605.

42. Cortese S, Kelly C, Chabernaud C, Proal E, Di Martino A, Milham MP, et al. Toward systems neuroscience of ADHD: A meta-analysis of $55 \mathrm{fMRI}$ studies. American Journal of Psychiatry. 2012; 169(10): 1038-55.

43. Brewer JA, Worhunsky PD, Gray JR, Tang YY, Weber J, Kober H. Meditation experience is associated with differences in default mode network activity and connectivity. Proc Natl Acad Sci USA. 2011; 108(50): 20254-9.

44. Germer CK, Siegel R, Fulton P. Mindfulness and psychonyanaponika therapy. New York: Guilford Press; 2005.

45. Felver JC, Tipsord JM, Morris MJ, Racer KH, Dishion TJ. The effects of mindfulness-based intervention on children's attention regulation. J Atten Disord. 2017; 21(10): 872-81.

46. Aadil M, Cosme RM, Chernaik J. Mindfulness-based cognitive behavioral therapy as an adjunct treatment of attention deficit hyperactivity disorder in young adults: A literature review. Cureus. 2017; 9(5): e1269. doi: 10.7759/cureus. 1269.

47. Roemer L, Lee JK, Salters-Pedneault K, Erisman SM, Orsillo SM, Mennin DS. Mindfulness and emotion regulation difficulties in generalized anxiety disorder: Preliminary evidence for independent and overlapping contributions. Behavior Therapy. 2009; 40(2): 14254.

48. Kallapiran K, Koo S, Kirubakaran R, Hancock K. Effectiveness of mindfulness in improving mental health symptoms of children and adolescents: a metaanalysis. Child and Adolescent Mental Health. 2015; 20(4): 182-94.

49. Raes F, Griffith JW, Van der Gucht K, Williams JMG. School-based prevention and reduction of depression in adolescents: A cluster-randomized controlled trial of a mindfulness group program. Mindfulness. 2014; 5(5): 477-86. 